\title{
Interaction required
}

\section{It may have profited from the increased interest in environmental issues, but ecology in Japan is still struggling to make ends meet. Robert Triendl crosses the divide within the discipline.}

A ccording to ecologists in Japan, two changes would improve their working lives. They would like to see more dialogue between basic and applied research, and they want to take a greater part in public debates and political decisions related to the environment. Like their colleagues in other industrialized countries, they have profited from the funding for ecological research that has increased along with concerns over issues such as biodiversity and global warming.

One example is Kyoto University's Centre for Ecological Research (CER), an inter-university research centre which is the first to be dedicated to ecology. Set up in 1992, the centre now hosts about 15 full and associate lecturers and some 70 postdoc and graduate students. Over the past few years, basic research in ecology has also benefited from a series of large-scale cooperative projects on ecosystems in Asia, such as tropical rainforests in Malaysia or Thailand. But most basic research in ecology in Japan remains confined to small university laboratories.

Research in ecology and environmental sciences was traditionally funded mainly by the Ministry of Education and, to a lesser extent, the former environmental agency. But during the early 1990s, agencies such as the New Energy Development Organization started to fund large-scale research efforts, often targeting applied research topics or risk assessment issues.

At the Institute for Environmental Sciences (IES) in Rokkasho Mura, where Japan's nuclear reprocessing plant is currently being built, scientists are building a small artificial habitat, similar to the US Biosphere 2 project. With an annual budget of some US\$50 million, the IES is now one of the best-funded environment-related research centres in Japan. After completion, scientists will trace the accumulation of radioactive substances in the environment.

But as Keiji Nitta, who directs the environmental simulation department at the IES, points out, the institute's facilities could be used to study a host of

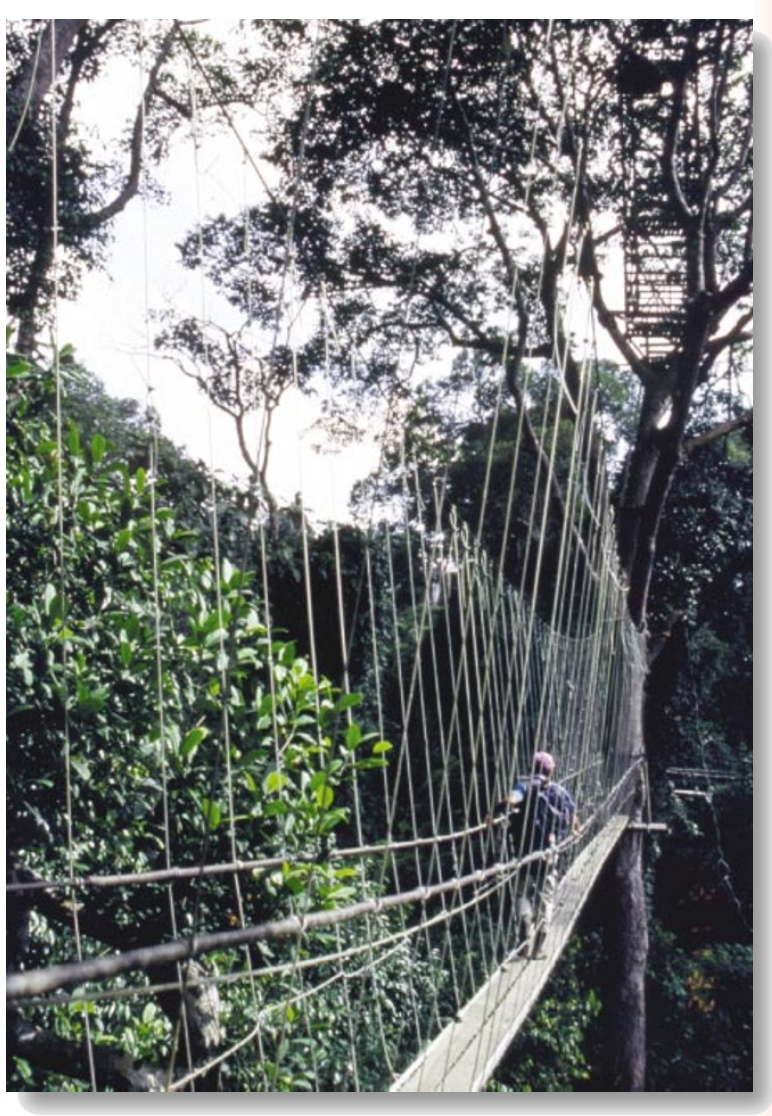

other questions. Given the institute's background and its source of funding, research on topics outside its immediate mission and collaborations with external scientists have not been encouraged. This is now slowly changing, says Nitta.

But collaboration between academic scientists and researchers working on more applied questions is not straightforward. Ecologists in Japan need to broaden their view and get more involved in questions relevant to real-world environmental issues, argues Nitta. Ecologists in Japan have tended to be highly specialized, with only limited interaction among the various branches of the field.

Norio Yamamura, director of the CER, agrees that many ecologists in Japan have been reluctant to engage in research on high-profile issues or to connect with policy-makers.

For young scientists there is often little choice. As an academic discipline, the job prospects for aspiring ecologists are not encouraging. The number of faculty positions is hardly growing and the number of research positions for ecologists outside academia is limited. The situation looks much better outside the realm of purely academic research.

The challenge remains to bridge these two worlds. More interaction between basic and applied research and higher visibility by the general public and political decision-makers will eventually benefit the whole field.

Robert Triendl is a freelance writer based in Tokyo. discipline. 